\title{
Reminiscences on Helicobacter pylori
}

\author{
Robin J Warren AC, MD, MB BS, FAA, FRCPA ${ }^{3}$
}

The saga of Helicobacter pylori began for me when I saw the bacteria, clearly growing in situ, in large numbers on the surface of the foveolar epithelium. The biopsy also showed severe chronic gastritis with marked active change in the foveolar epithelium. At the time, it was a "known fact" that bacteria could not grow in the stomach. My colleagues challenged me to find more cases if I really thought they were important. So I looked for them on all future gastric biopsies and, to my surprise, as well as everyone else's, I soon found them on about a third of the biopsies. Most were in smaller numbers than the first case, sometimes hard to see, but usually associated with some degree of active chronic gastritis as defined by Richard Whitehead. ${ }^{1,2}$

This active inflammation described by Whitehead is a "very striking feature," easily recognised, although usually not as gross as in his original illustrations. It involves a distinctive distortion of the foveolar epithelium together with polymorphonuclear leucocyte infiltration of the otherwise intact foveolar epithelium. I had been using it in my descriptions of gastric biopsies for some years when I first saw Helicobacter. I soon found these active changes were closely related to the infection. Since the bacteria grow on the surface of the epithelium, this is probably not surprising.

These active changes vary in severity tremendously. Some cases show changes like those illustrated by Whitehead. Usually the changes are much milder and often focal, but still basically similar. Some show minimal epithelial distortion and only occasional scattered intraepithelial polymorphs. In the absence of Helicobacter, foveolar polymorphs are almost never seen. Polymorphs are more common in the lamina propria and here they do not appear to be a specific feature.

The explanation for the epithelial change appears to lie in the close relationship between $H$. pylori and the microvilli on the surface of the foveolar cells. The bacteria tend to attach to the microvilli and destroy them

\footnotetext{
${ }^{3}$ Prof Warren is Emeritus Professor of Medicine at the University of Western Australia and the Royal Perth Hospital. Office of the Nobel Laureates, PO Box 3041, Broadway, Nedlands WA 6009 , Australia.
} 
(Figure 1). The microvilli contain bundles of filaments that attach to the top of the villi, pass down through the cells and attach to the cell base. This gives the cells a somewhat rigid structure that maintains the cell architecture. This architecture is still recognisable in cytological smears. On light microscopy, the normal cells have a flat top, with superficial mucus globules and a nucleus fixed at the base. When the microvilli are lost, the filaments are detached, the cells lose this rigid structure and become to a varying extent amoeboid. Severe changes resemble Whitehead's pictures, with nuclei floating at all levels instead of aligned at the cell bases, and long extensions of cytoplasm hanging out into the lumen. Mucus globules are usually reduced in number and also often scattered. These are the most severe changes. Usually the changes are similar but milder, often giving what I described as a "cobblestone" change to the normally flat surface of the foveolar epithelium on light microscopy.

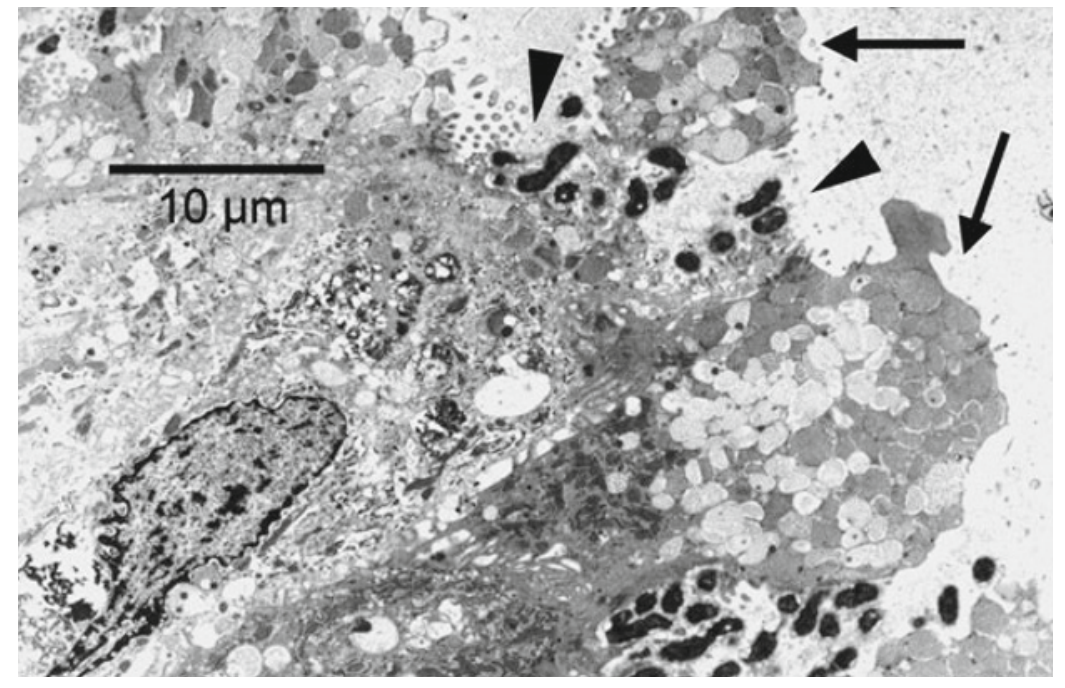

Fig. 1. Electron microscopy shows $H$. pylori attached to remaining microvilli (arrowheads). Two cells show almost complete destruction of microvilli with cytoplasm bulging into the lumen (arrows) - the cobblestone change seen on light microscopy with the active change.

I continued to study the bacteria on my own for two years before I met Barry Marshall. My letter to the Lancet ${ }^{3}$ was a summary of the paper I was writing when I met Barry and does not include any of our joint work. That 
is described in Barry's letter. ${ }^{4}$ One of the difficulties with my work was that the only material I had was the routine gastric biopsies I received. These were usually taken from localised lesions for which a diagnosis was required. The most frequent was gastric ulcer, to exclude or diagnose malignant change. An interesting aside is that biopsies were almost never taken from duodenal ulcer. They are almost never malignant. They were rarely mentioned on request forms. So in the pathology department we had no idea if a patient had a duodenal ulcer.

These biopsies taken from localised lesions, often ulcers, made it difficult to say for certain which changes were due to the nearby ulceration and which were related to the Helicobacter infection. One interesting feature was that the foveolar epithelium near an ulcer often showed a marked reduction in mucinogenesis. I consider the likely explanation is that the cells are proliferating, part of the healing process, and the mucus secretion is reduced in the proliferating cells. On this epithelium Helicobacter is usually either rare or absent, even though they may be plentiful on the foveolar epithelium elsewhere.

I did notice, however, that tiny intraepithelial colonies of the bacteria were often present in these cases. Careful examination with oil immersion microscopy revealed that the bacteria were actually within what I termed "microcrypts" (Figure 2). These consist of groups of adjacent foveolar cells forming a tiny pore in the epithelium. The top of the adjacent cells turn in towards each other. Bacteria in these microcrypts seem to be protected from the hostile gastric environment and appear healthy even without the overlying mucus. Normally the bacteria grow close to the surface of the foveolar cells, often attached to the sub-microscopic microvilli on the foveolar cell surface. Foveolar cells normally continuously secrete mucus, which forms a band about $1 \mathrm{~mm}$ thick. This functions in the stomach in a way analogous to the stratum corneum on the epidermis. The bacteria grow beneath this mucus and are protected by it. But in the absence of the normal mucus they seem to be protected by growing in these pores or microcrypts that form within the epithelium.

I believe these microcrypts do exist without the bacteria. However, when they are empty they are only virtual spaces, and are very difficult to see. I have seen several, by examining very carefully and focusing up and down with the oil immersion lens. They are only recognisable by the adjacent foveolar cells with turned-in tops. When there is a bacterial colony inside, especially with few bacteria on the surface, they are fairly easy to see. At low power, they are seen as scattered basophilic globules near the foveolar cell surface. Near an ulcer border the mucus secretion is often reduced with few bacteria on the surface. 


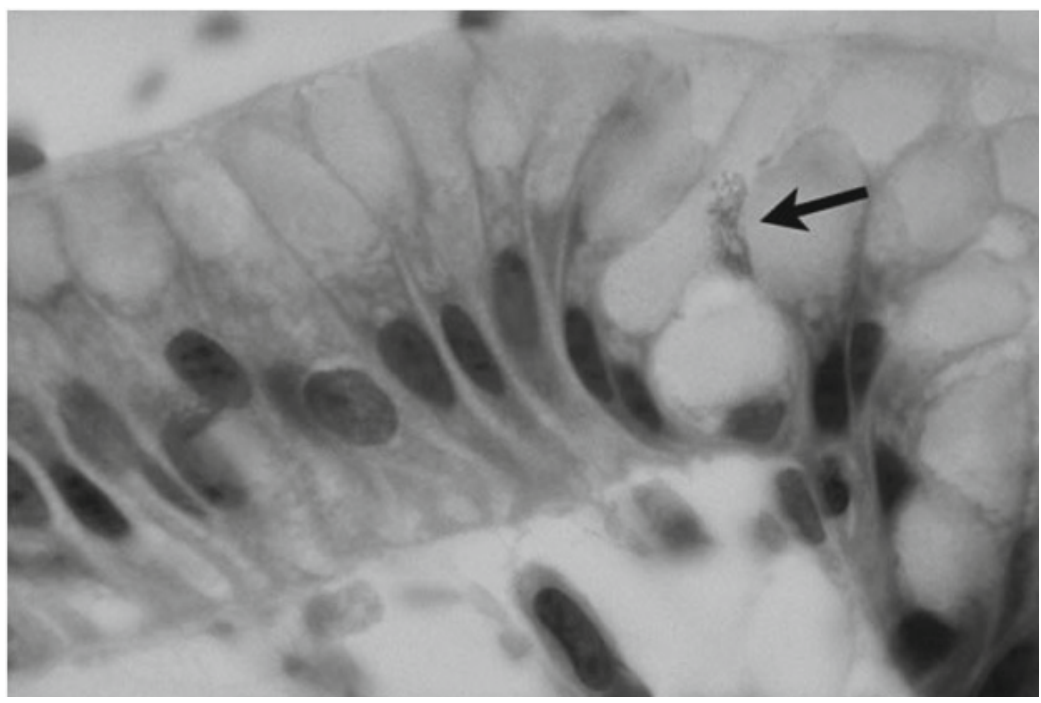

Fig. 2. There is a small colony of Helicobacter (arrow) in a microcrypt, a tiny intraepithelial diverticulum. The foveolar cells in this case show near normal mucus secretion. (H\&E x1200)

The microcrypts should be distinguished from tiny folds that are commonly seen in the foveolar epithelium. These show full thickness folding of the epithelium, including the basement membrane. They have a wider opening and probably do not provide a safe haven for the bacteria to grow. The microcrypts show little or no bulging of the associated epithelial surface and basement membrane. The superficial pore appears closed and presumably protects the bacteria beneath. This is only a small part of the whole Helicobacter picture, but it may be important in the survival of the bacteria.

These are some of the many observations I made on the histology associated with Helicobacter pylori infection. One of the prime reasons for the latter observation was probably one of the biggest difficulties I had before I met Barry Marshall. The biopsies were taken for the benefit of the patients, not for my research, and were often associated with gastric ulcers. This did make my work difficult, but even this can be useful, as I describe above. 


\section{REFERENCES}

1. Whitehead R, Truelove SC, Gear MWL. The histological diagnosis of chronic gastritis in fibreoptic gastroscope biopsy specimens. J Clin Pathol 1972; 25:1-11.

2. Whitehead R. Mucosal biopsy of the gastrointestinal tract. In: Bennington JL, ed. Major problems in pathology: Vol III, 2nd ed. Philadelphia: WB Saunders, 1979:20.

3. Warren JR. Unidentified curved bacilli on gastric epithelium in active chronic gastritis. (letter) Lancet 1983;i:1273.

4. Marshall BJ. Unidentified curved bacilli on gastric epithelium in active chronic gastritis. (letter) Lancet 1983;i:1273. 